\title{
Estimate of incidence and cost of recreational waterborne illness on United States surface waters
}

\author{
Stephanie DeFlorio-Barker ${ }^{1 *}$, Coady Wing ${ }^{2}$, Rachael M. Jones ${ }^{1}$ and Samuel Dorevitch ${ }^{1,3}$
}

\begin{abstract}
Background: Activities such as swimming, paddling, motor-boating, and fishing are relatively common on US surface waters. Water recreators have a higher rate of acute gastrointestinal illness, along with other illnesses including respiratory, ear, eye, and skin symptoms, compared to non-water recreators. The quantity and costs of such illnesses are unknown on a national scale.
\end{abstract}

Methods: Recreational waterborne illness incidence and severity were estimated using data from prospective cohort studies of water recreation, reports of recreational waterborne disease outbreaks, and national water recreation statistics. Costs associated with medication use, healthcare provider visits, emergency department (ED) visits, hospitalizations, lost productivity, long-term sequelae, and mortality were aggregated.

Results: An estimated 4 billion surface water recreation events occur annually, resulting in an estimated 90 million illnesses nationwide and costs of $\$ 2.2-\$ 3.7$ billion annually (central $90 \%$ of values). Illnesses of moderate severity (visit to a health care provider or ED) were responsible for over $65 \%$ of the economic burden (central $90 \%$ of values: \$1.4- \$2.4 billion); severe illnesses (result in hospitalization or death) were responsible for approximately $8 \%$ of the total economic burden (central 90\% of values: $\$ 108-\$ 614$ million).

Conclusion: Recreational waterborne illnesses are associated with a substantial economic burden. These findings may be useful in cost-benefit analysis for water quality improvement and other risk reduction initiatives.

Keywords: Water recreation, Economic burden, National estimate

\section{Background}

Surface water recreation in lakes, ponds, rivers, and oceans is popular in the US. According to the National Survey on Recreation and Environment (NSRE), over $61 \%$ (142 million people) of the US population over 16 years of age used waterbodies to participate in a range of non-motorized water sports like swimming, kayaking, and canoeing [1].

The enjoyment people get from surface water recreation is tempered by the risk of illness from exposure to polluted water. Water recreators have a higher incidence of acute gastrointestinal illness (AGI) and non-enteric illnesses, including respiratory, ear, eye, and skin symptoms than non-

\footnotetext{
* Correspondence: sdeflor2@uic.edu

${ }^{1}$ Division of Environmental and Occupational Health Sciences, School of Public Health, University of Illinois, 2121 W. Taylor, Chicago, Illinois, USA Full list of author information is available at the end of the article
}

water recreators [2-6]. Sporadic illnesses from water recreation often are mild and identified through epidemiologic studies [3, 7]. In contrast, outbreaks among surface water recreators are documented in the Waterborne Disease and Outbreak Surveillance System (WBDOSS) annually. From 2000 to 2010 WBDOSS recorded 102 outbreaks associated with untreated recreational water (excluding swimming pools and water parks), and more than 1559 cases of illness. WBDOSS is a passive outbreak surveillance system. Members of the public, clinicians, or clinical microbiology personnel are to notify health department personnel about suspected outbreaks. Health department personnel investigate to verify whether an outbreak has occurred and whether it is linked to water recreation. Recognized outbreaks constitute an unknown fraction of all waterborne disease outbreaks that occur [8]. 
To date, the literature does not describe the number of illnesses attributable to surface water recreation in the US or the costs of such illnesses per year. Without these estimates, costs of improved public health protections, beach monitoring and notification programs, or beach remediation efforts cannot be put into context. Assessments of economic burden from illnesses due to water recreation have been published in recent years though they are limited either in terms of data availability, a focus on a specific location [9], or focus on costs associated with hospitalization of illnesses thought to be transmitted by water, but not specifically through recreational water exposure [10]. We have recently described the severity [11] and costs [12] associated with sporadic cases of AGI in two large cohort studies of water recreation. Costs of AGI attributable to water recreation per 1000 recreators, ranged between $\$ 338$ and $\$ 1681$ for incidental-contact recreation (paddling, motor-boating, and fishing) and between $\$ 425$ and $\$ 2743$ for swimming/wading per 1000 recreators. Our primary objective in the present study was to construct an estimate of the national economic burden of surface water recreation in the US for sporadic and outbreak-associated illnesses.

\section{Methods}

\section{Overview}

To estimate the annual number of cases of illness (AGI, respiratory, ear, eye, and skin) attributable to surface water recreation, we first estimated the number of people who engage in surface water recreation annually. We combined estimates of the size of the water recreator population with estimates of rates of the occurrence of illness and the fraction of illnesses attributable to water recreation from cohort studies of swimming and incidental-contact recreation to form estimates of the number of sporadic illness that occur annually due to water recreation. Two cohort studies used to estimate sporadic cases of recreational waterborne illness in the US included the National Environmental and Epidemiological Assessment of Recreational Water (NEEAR, which addressed swimming) and the Chicago Health, Environmental Exposure, and Recreation Study (CHEERS, which addressed incidental-contact recreation, such as paddling, motor-boating, and fishing). NEEAR evaluated health outcomes among approximately 26,000 beachgoers at freshwater and marine water beaches in six states [4-6] between 2003 and 2009. CHEERS evaluated similar health outcomes of incidental-contact water recreation, enrolling over 11,000 participants at 39 locations in the Chicago, Illinois area between 2007 and 2009 [3]. These studies evaluated the health impacts of water recreation at locations impacted by human fecal pollution, among a large number of water recreators.
We defined illnesses in the analysis as being mild, moderate, or severe. Mild illnesses were defined as not having contact with a health care provider ( $\mathrm{HCP})$, while moderate illnesses were defined has having contact with a HCP, whether in an outpatient facility, or an emergency department (ED). Rates of mild and moderate illness were estimated using the two cohort studies. Severe illnesses were defined as illnesses resulting in hospitalization or death, and were estimated using WBDOSS outbreak surveillance data. Assumptions of FoodNet surveillance system researchers were used to account for underdiagnosis and underreporting of cases of severe illness in the outbreak surveillance system [13]. Costs for all levels of severity were estimated based on the use of over-the-counter (OTC) medication, prescription medication, and time missed from work. Moderate illnesses also included costs associated with relevant HCP or ED visits. Severe illnesses, also included costs of hospitalization (rates were estimated based on both WBDOSS outbreak data and published studies (Additional file 1: Table S1), death (using value of a statistical life (VSL) [14], as well as costs associated with other health consequences which developed due to the primary illness (sequelae). By multiplying the estimated number of cases of illness attributable to water recreation (recreation events $\times$ attributable risk) by the distribution of costs we arrived at a range of cost estimates for each illness type (mild, moderate, or severe). Monte Carlo simulation calculated 100,000 realized values of the potential cost of surface water recreation, allowing us to estimate the mean and central $90 \%$ of values (C90) (5th and 95th percentile of the distribution) of costs for mild and moderate gastrointestinal, respiratory, eye, ear, skin conditions, as well as pathogen-specific severe illnesses attributable to water recreation.

\section{Data sources: Number of water recreation events}

The number of swimmers/waders, paddlers, motorboaters, and anglers per year in the US were estimated using the proportion of the non-institutionalized US population over 16 years of age who engage in water recreation each year [1]. These proportions, combined with the total US non-institutionalized population in 2007, estimated by the US Census [15], yield the total number of water recreators in the US over 16 years. Estimates of the total number of water recreators 16 years and under were estimated based on the proportion of persons 16 and under, relative to the number of those over age 16 by activity in two studies of water recreation $[3,4,6]$. The estimated number of recreation events was calculated using national estimates of days of water recreation per water recreator by recreational activity [1]. 
Mild and moderate illness occurrence and severity NEEAR and CHEERS data demonstrate that among participants who developed AGI, over 50\% took OTC medications, $40 \%$ stayed home from work, school, or missed daily activities, almost $20 \%$ were in contact with a HCP, $10 \%$ took prescription medications, and $1 \%$ went to an ED [11]. Costs of AGI varied among water recreators, depending on whether illness resulted in lost activities (such as work) and the extent to which individuals with AGI utilized the healthcare system [12]. In addition to AGI, we also evaluated the occurrence and costs of ear, eye, skin, and respiratory symptoms, by calculating the attributable risks based on the two previous epidemiology studies (Additional file 1: Table S2). Severity and costs of these non-AGI illnesses were evaluated similarly (See Additional file 1) as was done previously [12].

\section{Severe illness occurrence and severity}

To estimate the number of hospitalizations and deaths due to each pathogen, we applied pathogen-specific hospitalization and death rates among laboratoryconfirmed illnesses (see Additional file 1: Table S1). Recognized outbreaks represent an unknown fraction of all outbreaks, and underreporting and underdiagnosis are threats to the accuracy of waterborne disease outbreak surveillance data. To mitigate underreporting bias, we used estimates of underreporting rates from validation studies to construct adjusted illness counts, which were then used to estimate the number of hospitalizations and deaths. In a study of foodborne outbreaks of gastrointestinal infections, Scallan et al. [13] found that for every case of illness identified during an outbreak, approximately 25.5 other cases were estimated to occur without being captured by the outbreak surveillance system. We used this multiplier of 25.5 to correct for the underreporting and underdiagnoses of pathogen-specific recreational waterborne illnesses under the assumption that generally the same types and severity of illnesses would be underreported and underdiagnosed at similar rates whether the source of the illness was waterborne or foodborne. Cases of vibriosis linked to surface water recreation identified in WBDOSS include outbreaks as well as single cases that occurred outside recognized outbreaks [16]. As a result, numbers of vibriosis cases are thought to be better estimated; and only an underreporting multiplier of 1.1 developed for foodborne gastrointestinal illness [13] was applied. Once the number of outbreak-related cases were estimated, we then approximated the proportion of these cases which would be hospitalized or would result in death, since our severe illness category only included hospitalizations and deaths due to recreational waterborne illness (Additional file 1: Table S5 and S10). No multipliers were used for cases of primary amoebic meningoencephalitis due to Naegleria fowleri, since the illness is nearly $100 \%$ fatal and is unlikely to go undiagnosed and unrecognized [17]. Hospitalization data and death data (distinct from counts of the number of cases in communities) can also underestimate the number of cases caused by specific pathogens. Therefore, to account for underdiagnosis and/or underreporting, namely, we doubled the number of hospitalizations and deaths $[13,18]$ realizing this multiplier is subject to uncertainty.

\section{Economic burden estimation}

Health-related costs among the projected number of ill water recreators were summarized for mild (no contact with $\mathrm{HCP}$ ), moderate (contact with $\mathrm{HCP}$ ), and severe (hospitalization or deaths identified from WBDOSS) waterborne illnesses using methods common in studies estimating total economic burden of ill health [19, 20]. Total costs associated with each outcome ( $i=$ [mild, moderate, severe]) were estimated according to Eq. 1, using the total cost of OTC medications $\left(O T C_{i}\right)$, prescription medications $\left(R x_{i}\right)$, $\mathrm{HCP}$ visits $\left(H C P_{i}\right)$, ED visits $\left(E D_{i}\right)$, hospitalizations (Hospi$t_{a l}$ ), sequelae (Sequelae $)_{i}$ ), indirect costs resulting from missing time from work ( Productivity $_{i}$ ), as well as costs associated with mortality, using the Value of a Statistical Life $\left(V S L_{i}\right)$ [14] due to illness. All costs were adjusted for inflation to 2007 dollars (the year when both NEEAR and CHEERS overlapped), using relevant consumer price index for medical care commodities (medications) and medical care services (medical and hospital services) [21]. Cost assumptions and data sources are described in the (Additional file 1: Table S1). Costs for ED visits or hospitalizations were estimated from the Nationwide Emergency Department Sample (NEDS) and Nationwide Inpatient Sample (NIS) respectively, aggregated by the Agency for Healthcare Research and Quality (AHRQ), by ICD-9-CM (Additional file 1: Table S3). Total excess costs per case due to the development of with sequelae were estimated for the following specific illnesses: Guillain-Barré syndrome (Campylobacter) [19, 22], hemolytic-uremic syndrome with or without end stage renal disease $(E$. coli 0157H7), [19, 20, 23], and reactive arthritis (Campylobacter, Shigella) [19, 24, 25].

$$
\begin{aligned}
\text { Cost }_{i}= & \text { OTC }_{I}+\text { Rx }_{i}+\text { HCP }_{i}+\text { ED }_{i}+\text { Hospital }_{i} \\
& + \text { Sequelae }_{i}+\text { Productivity }_{i}+\text { VSL }_{i}
\end{aligned}
$$

Rather than using point estimates to develop an estimate of the total economic burden, we used a stochastic approach using a Monte Carlo simulation. This simulation is an effort to account for inherent randomness in the many estimates involved in the analysis. A single run of the simulation works by randomly drawing a value from each of the distributions (Additional file 1: 
Tables S4-S8) from means and other moments reported in the literature or estimated from the cohort studies. With the selected parameters, numbers of ill recreators and costs are calculated and then stored. This process was repeated 100,000 times to yield an estimated mean costs and the 5th and 95th percentile of the distribution, or the central $90 \%$ of values (C90) around the mean. The simulation was conducted using Crystal Ball version 11.1.

\section{Results}

Approximately 4.04 billion surface water recreation events were estimated to occur annually in the US. People who engage in many of these activities tend to do so multiple times annually [1]. The largest number of person-days of water recreation are accounted for by swimming (1.9 billion, 47.7\%), followed by fishing (1.1 billion, 27.3\%) (Table 1).

Epidemiologic data indicates risk for developing AGI symptoms attributable to swimming/wading of approximately 15 cases per 1000 recreators (Table 2). The risk of AGI illness attributable to fishing is approximately 15 per 1000 , while the risk attributable to other incidental-contact water recreation activities is 6 per 1000. The attributable risks of respiratory, eye, ear, and skin symptoms varied by type of water recreation. Given the number of water recreation events (Table 1), and the activity-specific attributable risks (Table 2), we estimate that of the 50 million sporadic cases (outside of recognized outbreaks) of AGI illness attributable to water recreation, 29 million (57\%) are attributable to swimming and 16.5 million (32\%) are attributable to fishing (Table 3). Approximately 10 million cases each of respiratory, eye, ear, and skin illness attributable to water recreation occur annually. These cases are almost entirely in the context of swimming, with the exception of eye symptoms, which primarily occur in the context of motorboating. The vast majority of sporadic illnesses are mild in the sense that they do not result in contact with a HCP. Respiratory, eye, and ear symptoms were more likely to result in moderate illness involving HCP contact (Table 3). According the epidemiologic data, adults (aged 20-54) tend to experience the majority of mild illnesses, while children $(0$ 10) experience the majority of moderate illnesses (Additional file 1: Table S9). It is less clear how age effects those with severe illness who are hospitalized or who die as this information generally not publicly available. Based on outbreak data, we estimate that between 333 and 1696 hospitalizations and 16-67 deaths occur annually due to recreational waterborne illness (Additional file 1: Table S10).

Based on the distribution of illness severity in NEEAR and CHEERS, the number of cases of illness, and the cost of each severity category of illness, we estimate an annual economic burden of recreational waterborne illness of $\$ 2.9$ (C90: 2.2, 3.7) billion (Table 4). Lost productivity accounted for $\$ 663$ million (23\% of the total), due to the large number of individuals who could not attend work. Moderate severity illnesses account for a small percent of waterborne illness $(9.2 \%)$, yet accounted for the majority of the economic burden (C90: \$1.9 billion, or $65 \%$ of the total). Among those with moderate illness, HCP and ED visits accounted for $81 \%$ of the

Table 1 Estimated percent of the population that engages in each activity, and the number of water recreators and person-days of water activity

\begin{tabular}{|c|c|c|c|c|c|c|}
\hline Activity & $\begin{array}{l}\% \text { of population } \\
16 \text { and over }\end{array}$ & $\begin{array}{l}\text { Millions of Recreators } \\
16 \text { and over } \\
\text { (C90) }\end{array}$ & $\begin{array}{l}\% \text { of population } \\
\text { under } 16^{\mathrm{C}}\end{array}$ & $\begin{array}{l}\text { Millions of recreators } \\
\text { under } 16^{d} \\
(C 90)\end{array}$ & $\begin{array}{l}\text { Mean days per } \\
\text { recreator } \\
(\mathrm{C} 90)^{a}\end{array}$ & $\begin{array}{l}\text { Millions of } \\
\text { person days } \\
\text { (C90) }\end{array}$ \\
\hline Swimming & $41.5(40.9-42.0)$ & 96.9 (96.1-97.7) & $88.8(88.0-89.5)$ & $\begin{array}{l}56.3 \\
(55.8-56.7)\end{array}$ & $\begin{array}{l}12.6 \\
(12.3-12.9)\end{array}$ & $\begin{array}{l}1928.9 \\
(1882.2-1976.9)\end{array}$ \\
\hline Kayaking & $6.0(5.8-6.3)$ & $14.1(13.7-14.4)$ & $1.7(1.6-1.7)$ & $\begin{array}{l}1.1 \\
(1.0-1.1)\end{array}$ & $\begin{array}{l}5.6 \\
(5.3-6.0)\end{array}$ & $\begin{array}{l}84.4 \\
(78.5-91.2)\end{array}$ \\
\hline Rowing & $4.0(3.8-4.2)$ & $9.3(9.4-9.3)$ & $1.3(1.2-1.3)$ & $\begin{array}{l}0.8 \\
(0.8-0.8)\end{array}$ & $\begin{array}{l}5.5 \\
(5.0-6.0)\end{array}$ & $\begin{array}{l}55.8 \\
(54.1-57.6)\end{array}$ \\
\hline Canoeing & $9.7(9.4-10.0)$ & $22.7(22.2-23.1)$ & $4.9(4.8-5.0)$ & $\begin{array}{l}3.1 \\
(3.1-3.2)\end{array}$ & $\begin{array}{l}4.7 \\
(4.5-4.9)\end{array}$ & $\begin{array}{l}121.1 \\
(115.6-126.8)\end{array}$ \\
\hline Motor boating & $23.4(22.9-23.9)$ & $54.7(53.9-55.4)$ & $\begin{array}{l}12.7 \\
(12.5-12.8)\end{array}$ & $\begin{array}{l}8.0 \\
(7.9-8.1)\end{array}$ & $\begin{array}{l}11.9 \\
(11.2-12.3)\end{array}$ & $\begin{array}{l}745.8 \\
(719.0-772.7)\end{array}$ \\
\hline Fishing ${ }^{e}$ & 23.7 (23.2-23.9) & $55.3(54.6-56.1)$ & $\begin{array}{l}32.3 \\
(31.7-32.6)\end{array}$ & $\begin{array}{l}20.4 \\
(20.1-20.6)\end{array}$ & $\begin{array}{l}14.6 \\
(14.1-15.2)\end{array}$ & $\begin{array}{l}1105.1 \\
(1057.9-1152.3)\end{array}$ \\
\hline Total & & & & & & 4.041 \\
\hline
\end{tabular}

${ }^{\mathrm{a}}$ Cordell $2012[1]$

${ }^{\mathrm{b}}$ Estimated based of US noninstitutionalized population 16 and over (233.5 million) in 2007 [15]

c Estimated number of recreators under 16/Estimated US population under 16 (63.3 million in 2007) [15]

${ }^{d}$ Estimated based on the proportion of children under 16 in NEEAR and CHEERS and the number of adult recreators in the US population

e Assuming warm water fishing 
Table 2 Attributable risks (95\% Cl) for the development of symptoms among water recreators, by activity

\begin{tabular}{|c|c|c|c|c|c|c|c|c|c|}
\hline & \multicolumn{3}{|c|}{ Incidental-Contact: Fishing ${ }^{a}$} & \multicolumn{3}{|c|}{ Other Incidental-Contact ${ }^{\mathrm{b}}$} & \multicolumn{3}{|c|}{ Swimming/Wading ${ }^{c}$} \\
\hline & $\begin{array}{l}\text { Probability of } \\
\text { illness if exposed } \\
\text { water/fish/bait } \\
(95 \% \mathrm{Cl})\end{array}$ & $\begin{array}{l}\text { Probability } \\
\text { of illness if } \\
\text { unexposed } \\
(95 \% \mathrm{Cl})\end{array}$ & $\begin{array}{l}\text { Attributable } \\
\text { Risk } \\
(95 \% \text { Cl) }\end{array}$ & $\begin{array}{l}\text { Probability } \\
\text { of illness if } \\
\text { exposed to } \\
\text { water } \\
(95 \% \mathrm{Cl})\end{array}$ & $\begin{array}{l}\text { Probability } \\
\text { of illness if } \\
\text { unexposed } \\
(95 \% \mathrm{Cl})\end{array}$ & $\begin{array}{l}\text { Attributable } \\
\text { Risk } \\
(95 \% \mathrm{Cl})\end{array}$ & $\begin{array}{l}\text { Probability } \\
\text { of illness if } \\
\text { exposed to } \\
\text { water } \\
(95 \% \mathrm{Cl})\end{array}$ & $\begin{array}{l}\text { Probability } \\
\text { of illness if } \\
\text { unexposed } \\
(95 \% \mathrm{Cl})\end{array}$ & $\begin{array}{l}\text { Attributable } \\
\text { Risk } \\
(95 \% \mathrm{Cl})\end{array}$ \\
\hline AGl & $\begin{array}{l}0.053 \\
(0.039,0.065)\end{array}$ & $\begin{array}{l}0.038 \\
(0.031 \\
0.046)\end{array}$ & $\begin{array}{l}0.015 \\
(-0.003 \\
0.030)\end{array}$ & $\begin{array}{l}0.040 \\
(0.036 \\
0.046)\end{array}$ & $\begin{array}{l}0.034 \\
(0.028 \\
0.040)\end{array}$ & $\begin{array}{l}0.006 \\
(-0.002 \\
0.014)\end{array}$ & $\begin{array}{l}0.040 \\
(0.036 \\
0.043)\end{array}$ & $\begin{array}{l}0.025 \\
(0.022, \\
0.029)\end{array}$ & $\begin{array}{l}0.015 \\
(0.010,0.020)\end{array}$ \\
\hline Respiratory & $--^{d}$ & $-{ }^{d}$ & - & $\begin{array}{l}0.182 \\
(0.171 \\
0.192)\end{array}$ & $\begin{array}{l}0.210 \\
(0.196 \\
0.226)\end{array}$ & $-{ }^{\mathrm{e}}$ & $\begin{array}{l}0.054 \\
(0.050- \\
0.058)\end{array}$ & $\begin{array}{l}0.049 \\
(0.044 \\
0.054)\end{array}$ & $\begin{array}{l}0.005 \\
(-0.002,0.011)\end{array}$ \\
\hline Eye & $-{ }^{d}$ & $-{ }^{d}$ & - & $\begin{array}{l}0.081 \\
(0.074 \\
0.088)\end{array}$ & $\begin{array}{l}0.073 \\
(0.063, \\
0.083)\end{array}$ & $\begin{array}{l}0.008 \\
(-0.004 \\
0.019)\end{array}$ & $\begin{array}{l}0.029 \\
(0.027 \\
0.032)\end{array}$ & $\begin{array}{l}0.029 \\
(0.026 \\
0.032)\end{array}$ & $-{ }^{e}$ \\
\hline Ear & $-{ }^{d}$ & $-{ }^{d}$ & - & $\begin{array}{l}0.017 \\
(0.014, \\
0.020)\end{array}$ & $\begin{array}{l}0.017 \\
(0.011, \\
0.020)\end{array}$ & $-{ }^{e}$ & $\begin{array}{l}0.016 \\
(0.014, \\
0.018)\end{array}$ & $\begin{array}{l}0.012 \\
(0.010, \\
0.015)\end{array}$ & $\begin{array}{l}0.004 \\
(-0.0001 \\
0.006)\end{array}$ \\
\hline Skin & $\begin{array}{l}0.087 \\
(0.070,0.102)\end{array}$ & $\begin{array}{l}0.095 \\
(0.084 \\
0.107)\end{array}$ & $-{ }^{e}$ & $\begin{array}{l}0.083 \\
(0.075 \\
0.090)\end{array}$ & $\begin{array}{l}0.093 \\
(0.082 \\
0.104)\end{array}$ & $-{ }^{e}$ & $\begin{array}{l}0.029 \\
(0.027 \\
0.032)\end{array}$ & $\begin{array}{l}0.023 \\
(0.020 \\
0.027)\end{array}$ & $\begin{array}{l}0.006 \\
(0.002,0.010)\end{array}$ \\
\hline
\end{tabular}

${ }^{a}$ Comparing those who fish to the unexposed group (non-water recreators) in CHEERS

${ }^{b}$ Comparing those who engage in incidental-contact water recreation (kayaking, canoeing, boating, rowing) to unexposed group (non-water recreators) in CHEERS

${ }^{c}$ Comparing those who have any contact with beach water (swimmers/waders) to the unexposed group (non-water recreators) in NEEAR

${ }^{d}$ Anglers not expected to have excess risk of respiratory, eye, ear, or skin illness due to nature of fishing exposure

${ }^{e}$ No AR calculated, since no excess of illness among the exposed compared to unexposed

economic cost. While death was rare, the costs of lost life accounted for $97 \%$ of the estimated \$233.7 (C90: 108.5, 613.9) million attributed to severe illness events. The cost of illness per case of illness ranged from $\$ 9.50$ (C90: 8.62-10.34) for with mild illness, \$233.38 (C90: 202.30-277.15) for moderate illness, and \$302,685 (C90: $156,803-775,605)$ for the most severe illnesses. The complete breakdown of economic burden by illness type can be found in the (Additional file 1: Tables S11-S13).

\section{Discussion}

We estimate that swimming/wading, paddling, motorboating, and fishing in US surface waters account for over 90 million cases of GI, respiratory, ear, eye, or skin-related illnesses with a wide range of severity. The estimated annual economic burden of recreational waterborne illnesses is approximately $\$ 2.9$ (C90: 2.2, 3.7) billion. While mild illness was common, approximately $65 \%$ of the cost was attributable

Table 3 Estimated annual number of cases of mild and moderate illness (C90) due to water recreation, by activity, in millions ${ }^{\text {a }}$

\begin{tabular}{|c|c|c|c|c|c|}
\hline Activity & $A G l$ & Respiratory & Eye & Ear & Skin \\
\hline Swimming & $\begin{array}{l}29.14 \\
(23.09-34.58)\end{array}$ & $\begin{array}{l}9.22 \\
(1.29-16.66)\end{array}$ & $-^{b}$ & $\begin{array}{l}6.87 \\
(2.62-10.25)\end{array}$ & $\begin{array}{l}12.06 \\
(6.99-16.87)\end{array}$ \\
\hline Kayaking & $\begin{array}{l}0.54 \\
(0.11-0.97)\end{array}$ & $-{ }^{\mathrm{b}}$ & $\begin{array}{l}0.63 \\
(0.04-1.29)\end{array}$ & $-{ }^{b}$ & $-b$ \\
\hline Rowing & $\begin{array}{l}0.38 \\
(0.03-0.76)\end{array}$ & $-{ }^{b}$ & $\begin{array}{l}0.42 \\
(0.03-0.85)\end{array}$ & $-b$ & $-b$ \\
\hline Canoeing & $\begin{array}{l}0.78 \\
(0.15-1.38)\end{array}$ & $-{ }^{b}$ & $\begin{array}{l}0.91 \\
(0.05-1.84)\end{array}$ & $-b$ & $-b$ \\
\hline Motor boating & $\begin{array}{l}4.77 \\
(0.94-8.50)\end{array}$ & $-^{b}$ & $\begin{array}{l}5.59 \\
(0.36-11.31)\end{array}$ & $-^{b}$ & $-b$ \\
\hline Fishing & $\begin{array}{l}15.27 \\
(4.12-25.12)\end{array}$ & $-{ }^{b}$ & $-^{\mathrm{b}}$ & $-b$ & $-b$ \\
\hline Total & $\begin{array}{l}50.95 \\
(36.59-63.42)\end{array}$ & $\begin{array}{l}9.22 \\
(1.29-16.66)\end{array}$ & $\begin{array}{l}7.55 \\
(0.49-15.28)\end{array}$ & $\begin{array}{l}6.87 \\
(2.62-10.25)\end{array}$ & $\begin{array}{l}12.06 \\
(6.99-16.87)\end{array}$ \\
\hline Moderate Severity ${ }^{c}$ & $7.2 \%$ & $13.7 \%$ & $10.4 \%$ & $24.3 \%$ & $5.4 \%$ \\
\hline
\end{tabular}

${ }^{a}$ Calculated based on estimated number of water recreation events and the attributable risk of illness, may not sum to estimated totals due to rounding

${ }^{\mathrm{b}}$ No excess illnesses expected, based on the attributable risk

c Percent with moderate severity illness (those who contact their HCP or go to an ED) 
Table 4 Total and per-case cost estimates (in millions of US dollars) of mild, moderate, and severe waterborne illnesses; mean (C90) ${ }^{a}$

\begin{tabular}{|c|c|c|c|c|c|}
\hline & & Mild & Moderate & Severe & \\
\hline \multirow[t]{11}{*}{ Total cost in Millions of US Dollars } & OTC medication & $\begin{array}{l}242.2 \\
(182.0-295.1)\end{array}$ & $\begin{array}{l}33.5 \\
(22.7-42.4)\end{array}$ & $\begin{array}{l}0.004 \\
(0.001-0.009)\end{array}$ & \\
\hline & Prescription medication & $\begin{array}{l}53.1 \\
(26.3-67.5)\end{array}$ & $\begin{array}{l}126.0 \\
(82.5-160.0\end{array}$ & $\begin{array}{l}0.03 \\
(0.01-0.08)\end{array}$ & \\
\hline & Doctor office visit & - & $\begin{array}{l}615.0 \\
(427.3-803.3)\end{array}$ & $\begin{array}{l}0.16 \\
(0.06-0.36)\end{array}$ & \\
\hline & ED & - & $\begin{array}{l}924.9 \\
(631.0-1226.7)\end{array}$ & $\begin{array}{l}0.22 \\
(0.09-0.50)\end{array}$ & \\
\hline & Hospitalization & - & - & $\begin{array}{l}6.79 \\
(3.19-14.07)\end{array}$ & \\
\hline & Death & - & - & $\begin{array}{l}225.79 \\
(103.55-599.07)\end{array}$ & \\
\hline & Sequelae & - & - & $\begin{array}{l}0.38 \\
(0.03-1.44)\end{array}$ & \\
\hline & Lost Productivity & $\begin{array}{l}461.3 \\
(342.2-586.5)\end{array}$ & $\begin{array}{l}201.1 \\
(146.2-286.5)\end{array}$ & $\begin{array}{l}0.31 \\
(0.13-0.69)\end{array}$ & \\
\hline & Total & $\begin{array}{l}756.7 \\
(568.3-928.3)\end{array}$ & $\begin{array}{l}1900.5 \\
(1393.6-2400.6)\end{array}$ & $\begin{array}{l}233.68 \\
(108.49-613.95)\end{array}$ & \\
\hline & $\begin{array}{l}\text { Cost per case } \\
\text { in US Dollars }\end{array}$ & $\begin{array}{l}9.50 \\
(8.62-10.34)\end{array}$ & $\begin{array}{l}233.38 \\
(202.30-277.15)\end{array}$ & $\begin{array}{l}302,685.57 \\
(156,803.58-775,605.39)\end{array}$ & \\
\hline & & \multicolumn{3}{|c|}{ Total cost of Recreational Waterborne Illness in Millions } & $\begin{array}{c}2890.9 \\
(2206.0-3663.7)\end{array}$ \\
\hline
\end{tabular}

${ }^{a}$ Estimated costs in 2007 dollars, may not sum to estimated totals due to rounding

to illness that resulted in contact with an HCP or evaluation in an ED.

Dwight et al. [9] estimated the annual economic burden (direct and indirect costs) due to water recreation at two beaches in Orange County, California to be $\$ 3.3$ million in 2001 dollars (\$3.9 million in 2007 dollars) based on lost productivity and healthcare office visit costs. In the current analysis, we estimated 1.9 billion swimming events occur annually in the US (Table 1). An estimated 5.5 million swimming events occur annually at Orange County beaches [26], or approximately $0.3 \%$ of the swimming events in the US. If costs estimated by Dwight and colleagues were scaled up, the national estimate of the annual economic burden due to swimming in surface water would be more than $\$ 1$ billion. In contrast to the current study, Dwight et al. did not include costs associated with hospitalization, deaths, or medications, and was focused on adults 18 years of age and older, yet their estimate is still within the margin of error for our estimate (\$1.7 (C90: 1.4, 2.0) billion) among swimmers/waders. Both cohort studies in the current analysis included children, which could also account for the cost differential between our analysis and the one conducted by Dwight and colleagues, especially since children (aged 0-10) appear to experience the majority of moderate illnesses (Additional file 1: Table S9).

Another study by Given et al. (2006) examined the number of excess gastrointestinal illnesses due to swimming at 28 beaches in southern California [27]. This study estimated that 627,800 and $1,479,200$ excess gastrointestinal illnesses occur annually due to swimming in Los Angeles and Orange County California, or between 2 and $5 \%$ of our national estimate. Using the per-case cost estimate from Dwight et al. [9], costs (time missed from work, doctor visits) Given et al. (2006) estimated costs of GI illness to range from $\$ 21$ to $\$ 51$ million in 2000 dollars, or about $1-3 \%$ of our national estimate of costs attributable to gastrointestinal illness. Therefore, costs estimated by Given et al. (2006) are consistent with our national estimate, despite not including information regarding hospitalization or medication use.

Collier et al. [10] estimated that US hospitalization costs for illnesses caused by microbes primarily transmitted by water (giardiasis, cryptosporidiosis, Legionnaires' disease, otitis externa, and non-tuberculous mycobacterial infection) were $\$ 970$ million annually and illnesses only partially transmitted by water (campylobacteriosis, salmonellosis, shigellosis, hemolytic-uremic syndrome, and toxoplasmosis) accounted for $\$ 860$ million in hospitalizations annually. In that study, researchers estimated the annual number of infections caused by specific pathogens, then estimated the proportion possibly due to water exposure (not specifically surface water recreation). In the present study, we estimated costs due to hospitalizations from recreation in untreated surface water to be $\$ 6.8$ (C90: 3.2 to $\$ 14.1$ ) million, or approximately $4 \%$ of the Collier et al. 
estimate. This discrepancy between the two estimates could be largely due to their inclusion of illnesses that may have been acquired via drinking water, swimming pools, and water parks, in addition to surface water recreation, or not via water exposure. From 2007 to 2008, approximately $90 \%$ of all outbreaks and $95 \%$ of all outbreak cases were associated with treated recreational water, such as swimming pools, spas, and water parks [28]. Also, pathogens responsible for sporadic illness are rarely identified [29]. Thus, estimation of costs of sporadic illness that rely upon identifying specific pathogens in stool samples of ill recreators will underestimate the costs overall in the absence of multipliers that account for underdiagnosis and underreporting.

Foodborne illness has been estimated to cost between \$51-77 billion each year, depending on assumptions regarding lost productivity and pain and suffering [19]. Cost of illness due to surface water recreation would be expected to be a fraction of the costs of foodborne illnesses, as food consumption is a daily occurrence, unlike water recreation.

A strength of the present study is large prospective cohort studies containing a combined over 35,000 participants were used to estimate risk of illness attributable to surface water recreation. These studies obtained data directly from those engaged in water recreation regarding illness, healthcare utilization, and lost productivity. Prior studies of the cost of waterborne illness that utilized healthcare claims and hospital discharge data [10] but had no available information regarding water exposure. The present study used a combination of cohort and outbreak data with known water exposure, and other components of economic burden, such as costs associated with lost productivity and medication use. Unlike the prior estimate of the cost of waterborne illness at a California beach [9], the present study is likely more representative of surface water recreation nationally, as it included data from freshwater and marine beaches, as well as urban inland waters. Furthermore, we incorporated additional costs components in the estimate (hospitalizations, sequelae, and mortality).

Our findings are subject to several limitations. The accuracy of the economic burden estimate depends on the accuracy of the estimation of the total number of people in the US engaging in water recreation and an estimate of the total number of person-days associated with a particular water activity. We only used estimates of the number of warmwater fishing events, (fishing in rivers, streams, lakes, and oceans); less common types of fishing, including andromodous, coldwater, and saltwater, [1], were not considered. We also focused primarily on five major health outcomes (AGI, respiratory, ear, eye, and skin symptoms) in addition to severe pathogenspecific illnesses. Harmful algal blooms (HABs) produce toxins that can result in AGI, respiratory, skin, eye, ear, and neurological symptoms [30], and have been estimated to be responsible for $\$ 0.5-\$ 4$ million in respiratory ED visits in Sarasota Country, Florida annually [31]. Exposures to HABs may have a significant economic impact, but were not included in our analysis. We considered sequelae (hemolytic-uremic syndrome with or without end stage renal disese, reactive arthritis, and Guillain-Barré syndrome) as a result of illness among those who were hospitalized. However, we did not consider costs of reactive arthritis, which can be treated in an outpatient setting, for any individuals who were not hospitalized, which could have also underestimated costs among those with moderate illness.

In addition, our analysis assessed risks for individual illnesses, but it is possible that water recreation can result in the development of more than one type of illness (ie AGI and respiratory illness). While this would likely not impact the attributable fraction, it could be expected to have an impact on cost. For example, a person experiencing both AGI and respiratory symptoms who saw a HCP or visited an ED, most likely would have been treated for both symptoms concurrently, opposed to being charged for two individual visits. This could have resulted in an overestimation of economic burden. Additionally, we were not able to differentiate individuals whose symptoms were due to infection versus other causes; likewise, our reliance on symptom reporting means that we were not able to estimate the number of asymptomatic infections.

In our analysis, we did not estimate economic burden according to age category. Since children are more likely to have contact with surface water [32] and are at an increased risk of illness [33], we would expect that some of the economic burden for water recreation to be among children. We found that according epidemiology studies, a large portion of mild illness is among adults aged 20-54, while the majority of moderate illness is among children aged 0-10 (Additional file 1: Table S9). While we expect risk to differ by age, whether the costs differ according to age is less clear. With regard to lost productivity for mild and moderate illnesses, we used an estimate of the mean (and the 5th and 95th percentile of the distribution) estimate of time missed from work estimated from epidemiology studies, which already takes into account the distribution of the age of those who become ill. However, we know less about the age distribution among those who develop severe (hospitalizations/ death) illnesses following water recreation.

CHEERS and NEEAR were conducted at study locations that were likely impacted by human fecal pollution (particularly CHEERS [34]). Thus, the attributable risks calculated within the context of these studies may have potentially overestimated the risk of recreational 
waterborne illnesses relative to surface water recreation overall. For example, illness rates at Boqueròn beach in Puerto Rico, had lower concentrations of fecal indicators and observed illness rates were much lower than those in other NEEAR sites [35, 36], However, Boquerón is atypical of US beaches as it is tropical and symptoms following water recreation at Boquerón beach have been strongly linked to cyanobacteria [37], as opposed to fecal indicators. Water quality at NEEAR beaches generally met local water quality criteria and health risks observed there should reflect those at comparable beaches elsewhere. The range of water quality observed at waters where recreation took place in the epidemiologic studies is well within those described in a national summary of water quality [38]. It is reasonable to assume that as water quality improves, economic burden would decrease, yet further study is necessary to make this conclusion.

In addition, since the attributable risks were based on epidemiologic studies, there is a possibility of overreporting of illness if they had at baseline concerns about health risks due to water recreation, a phenomenon referred to as risk perception bias [39]. The use of the distributions of the attributable risks may allow for some degree of heterogeneity among beachgoers. Some attributable risks confidence intervals estimated for specific outcomes include zero (Table 2). To be conservative, we included these negative values at the lower bound in our Monte Carlo simulation. When we truncated risk at zero, we did not observe significant differences in the mean costs or in the C90.

Our cost estimates were approximated using 2007 USD. We chose to estimate the economic burden based on the year 2007 since it was a year in which several of our data sources overlapped. Accounting for inflation or 2007 USD estimate of $\$ 2.9(2.2,3.7)$ billion would be approximately $\$ 3.4(2.6,4.4)$ billion in 2017 USD. However, since there have been several changes to the healthcare system in recent years, it is inappropriate to express our estimate in more recent dollars.

The use of outbreak and passive surveillance multipliers based on foodborne illness data may not be ideal for adjusting for undercounting of recreational waterborne outbreaks. Currently, extensive surveillance data exists for foodborne illnesses, which were used to construct the multipliers [14]. Active surveillance systems for recreational waterborne illnesses do not exist in the US and it is unknown whether outbreak and passive surveillance multipliers are appropriate for recreational waterborne illness. However, these multipliers, based on several ratios of laboratory-confirmed cases of foodborne illness to cases identified through foodborne outbreak surveillance, are currently the best available.

\section{Conclusions}

The annual economic burden due to surface water recreation ranges between $\$ 2.2-3.7$ billion. Estimates of costs of prevention activities (beach monitoring and notification programs), and reduction of wastewater and storm-water discharges near beaches, should be viewed in context of this burden estimate. To date, approximately $\$ 140$ million has been allocated toward beachwater protection programs since 2001 [40] or about $\$ 10$ million annually, a small fraction of annual estimated illness burden. Efforts to reduce severity of illness among water recreators should be explored to reduce total economic burden and encourage more individuals to enjoy surface water recreation. Furthermore, we hope that future investigations build upon our work by estimating the health care costs saved as a function of improvements in water quality.

\section{Additional file}

\begin{abstract}
Additional file 1: Table S1. Data sources and assumptions utilized in calculating the economic burden of recreational waterborne illness. Table S2. Covariates used in logistic regression model to estimate attributable risk. Table S3. ICD-9-CM codes to determine ED and hospital costs. Table S4. Parameters used to estimate the number of mild and moderate illnesses. Table S5. Parameters used to estimate the number of severe illnesses. Table S6. Parameters used to estimate the cost of mild illness. Table S7. Parameters used to estimate the cost of moderate illness. Table S8. Parameters used to estimate the cost of severe illness. Table S9. Proportion of mild and moderate illnesses by age category. Table S10. Estimated number of outbreak cases, hospitalizations, and deaths due to water recreation (C90). Table S11. Total cost of mild waterborne illness; mean (C90). Table S12. Total cost of moderate waterborne illness; mean (C90). Table S13. Total cost of severe waterborne illness; mean (C90). (DOCX $147 \mathrm{~kb})$
\end{abstract}

\section{Abbreviations}

AGl: Acute gastrointestinal illness; AHRQ: Agency for Healthcare Research and Quality; C90: Central 90\% of values; CHEERS: Chicago Health, and Environmental Exposure, and Recreation Study; ED: Emergency department; HAB: Harmful algal bloom; HCP: Health care provider; NEDS: Nationwide Emergency Department Sample; NEEAR: National Environmental and Epidemiological Assessment of Recreational Water; NIS: Nationwide Inpatient Sample; NSRE: National Survey on Recreation and Environment; OTC: Overthe-counter; VSL: Value of a statistical life; WBDOSS: Waterborne Disease and Outbreak Surveillance System

\section{Acknowledgements}

Many thanks to Ms. Yi-Ting Chen for her help with data collection.

\section{Funding}

The CHEERS study research reported here was funded by the Metropolitan Water Reclamation District of Greater Chicago. A peer review panel for this study was supported by the Water Environment Research Foundation. Support for analyses was provided by the U.S. Environmental Protection Agency (EPA) STAR agreement (RD-83478901). The contents of this work on CHEERS are solely the responsibility of the grantee and do not necessarily represent the official views of the U.S. EPA. Further, the U.S. EPA does not endorse the purchase of any commercial products or services mentioned herein.

\section{Availability of data and materials}

The economic and outbreak data are available publicly. The epidemiologic data are available from the corresponding author on reasonable request. 


\section{Authors' contributions}

SDB conceived of the study, conducted data analysis, and prepared the manuscript for publication; CW and RJ participated in the interpretation of the results; SD conceived of the study, participated in manuscript preparation, and interpretation of results. All authors read and approved the final manuscript

\section{Ethics approval and consent to participate}

All participants provided informed verbal consent. Approval for conduction of the epidemiology studies was acquired from the institutional review boards at the University of Illinois at Chicago, the Center for Disease Control and Prevention, and the University of North Carolina, Chapel Hill for all study locations.

\section{Consent for publication}

No individual's personal data are within the manuscript.

\section{Competing interests}

All authors declare that they have no competing interests.

\section{Publisher's Note}

Springer Nature remains neutral with regard to jurisdictional claims in published maps and institutional affiliations.

\section{Author details}

'Division of Environmental and Occupational Health Sciences, School of Public Health, University of Illinois, 2121 W. Taylor, Chicago, Illinois, USA. ${ }^{2} S c h o o l$ of Public Health and Environmental Affairs, Indiana University, Bloomington, Indiana, USA. ${ }^{3}$ Institute for Environmental Science and Policy, University of Illinois, Chicago, Illinois, USA.

\section{Received: 10 July 2017 Accepted: 8 December 2017}

\section{Published online: 09 January 2018}

\section{References}

1. Cordell HK: Outdoor recreation trends and futures: a technical document supporting the Forest Service 2010 RPA assessment. In. Asheville: Department of Agriculture Forest Service; 2012: 167.

2. Colford JM, Wade TJ, Schiff KC, Wright CC, Griffith JF, Sandhu SK, Burns S, Sobsey M, Lovelace G, Weisberg SB. Water quality indicators and the risk of illness at beaches with nonpoint sources of fecal contamination. Epidemiology. 2007;18(1):27-35.

3. Dorevitch S, Pratap P, Wroblewski M, Hryhorczuk DO, Li H, Liu LC, Scheff PA. Health risks of limited-contact water recreation. Environ Health Perspect. 2012;120(2):192-7.

4. Wade TJ, Calderon RL, Brenner KP, Sams E, Beach M, Haugland R, Wymer L, Dufour AP. High sensitivity of children to swimming-associated gastrointestinal illness: results using a rapid assay of recreational water quality. Epidemiology. 2008:19(3):375-83.

5. Wade TJ, Calderon RL, Sams E, Beach M, Brenner KP, Williams AH, Dufour AP. Rapidly measured indicators of recreational water quality are predictive of swimming-associated gastrointestinal illness. Environ Health Perspect. 2006;114(1):24-8.

6. Wade TJ, Sams E, Brenner KP, Haugland R, Chern E, Beach M, Wymer L, Rankin CC, Love D, Li Q, et al. Rapidly measured indicators of recreational water quality and swimming-associated illness at marine beaches: a prospective cohort study. Environ Health. 2010a;9:66.

7. Wiedenmann A, Kruger P, Dietz K, Lopez-Pila JM, Szewzyk R, Botzenhart K. A randomized controlled trial assessing infectious disease risks from bathing in fresh recreational waters in relation to the concentration of Escherichia Coli, intestinal enterococci, Clostridium Perfringens, and somatic coliphages. Environ Health Perspect. 2006;114(2):228-36.

8. Hlavsa MC, Roberts VA, Kahler AM, Hilborn ED, Wade TJ, Backer LC, Yoder JS. Recreational water-associated disease outbreaks-United States, 2009-2010. MMWR. 2014;63(1):6

9. Dwight RH, Fernandez LM, Baker DB, Semenza JC, Olson BH. Estimating the economic burden from illnesses associated with recreational coastal water pollution: a case study in Orange County, California. J Environ Manag. 2005; 76(2):95-103.

10. Collier SA, Stockman LJ, Hicks LA, Garrison LE, Zhou FJ, Beach MJ. Direct healthcare costs of selected diseases primarily or partially transmitted by water. Epidemiol Infect. 2012;140(11):2003-13.
11. DeFlorio-Barker S, Wade TJ, Turyk M, Dorevitch S. Water recreation and illness severity. J Water Health. 2016;14(5):713-26.

12. DeFlorio-Barker S, Wade TJ, Jones RM, Friedman LS, Wing C, Dorevitch S. Estimated costs of sporadic gastrointestinal illness associated with surface water recreation: a combined analysis of data from NEEAR and CHEERS studies. Environ Health Perspect. 2016;125(2):215.

13. Scallan E, Hoekstra RM, Angulo FJ, Tauxe RV, Widdowson MA, Roy SL, Jones $J$, Griffin PM. Foodborne illness acquired in the United States-major pathogens. Emerg Infect Dis. 2011;17(1):7-15.

14. US EPA USEPA. Guidelines for preparing economic analysis. In. Edited by economics NCfE. Washington, DC: Office of Policy, U.S. Environmental Protection Agency; 2010

15. US Census. Current population survey, annual social and economic supplement, 2007. In.; 2009. https://www.census.gov/prod/techdoc/cps/ cpsmar07.pdf.

16. CDC (Centers for Disease Control and Prevention): Cholera and other Vibrio illness surveillance overview. In. Atlanta: US Department of Health and Human Services; 2012.

17. Yoder JS, Eddy BA, Visvesvara GS, Capewell L, Beach MJ. The epidemiology of primary amoebic meningoencephalitis in the USA, 1962-2008. Epidemiol Infect. 2010;138(07):968-75.

18. Mead PS, Slutsker L, Dietz V, McCaig LF, Bresee JS, Shapiro C, Griffin PM, Tauxe RV. Food-related illness and death in the United States. Emerg Infect Dis. 1999;5(5):607

19. Hoffmann S, Batz MB, Morris JG Jr. Annual cost of illness and qualityadjusted life year losses in the United States due to 14 foodborne pathogens. J Food Prot. 2012;75(7):1292-302.

20. Scharff RL. Economic burden from health losses due to foodborne illness in the United States. J Food Protect. 2011;75(1):123-31.

21. BLS (Bureau of Labor Statistics): Measuring price change for medical care in the CPI [https://www.bls.gov/cpi/factsheets/medical-care.htm]. Accessed 15 Oct 2014

22. Frenzen PD. Economic cost of Guillain-Barre syndrome in the United States. Neurology. 2008;71(1):21-7

23. Frenzen PD, Drake A, Angulo FJ. The emerging infections program Foodnet working G: economic cost of illness due to Escherichia Coli:O157 infections in the United States. J Food Protect. 2005;68(12):2623-30.

24. Glennas A, Kvien TK, Melby K, Overbøo A, Andrup O, Karstensen B, Thoen JE. Reactive arthritis: a favorable 2 year course and outcome, independent of triggering agent and HLA-B27. J Rheumatol. 1994;21(12):2274-80.

25. Townes JM, Deodhar AA, Laine ES, Smith K, Krug HE, Barkhuizen A, Thompson $M E$, Cieslak PR, Sobel J. Reactive arthritis following culture-confirmed infections with bacterial enteric pathogens in Minnesota and Oregon: a populationbased study. Ann Rheum Dis. 2008;67(12):1689-96.

26. Turbow DJ, Osgood ND, Jiang SC. Evaluation of recreational health risk in coastal waters based on enterococcus densities and bathing patterns. Environ Health Perspect. 2003;111(4):598-603.

27. Given S, Pendleton $L H$, Boehm AB. Regional public health cost estimates of contaminated coastal waters: a case study of gastroenteritis at Southern California beaches. Environ Sci Technol. 2006:40(16):4851-8.

28. Hlavsa MC, Hilborn ED, Wade TJ, Beach MJ, Yoder JS, Roberts VA, Anderson AR, Hill VR, Kahler AM, Orr M, et al. Surveillance for waterborne disease outbreaks and other health events associated with recreational water United States, 2007-2008. MMWR. 2011:60(12):1-32.

29. Dorevitch S, Dworkin MS, DeFlorio SA, Janda WM, Wuellner J, Hershow RC Enteric pathogens in stool samples of Chicago-area water recreators with new-onset gastrointestinal symptoms. Water Res. 2012;46(16):4961-72.

30. Hilborn ED, Roberts VA, Backer L, DeConno E, Egan JS, Hyde JB, Nicholas DC, Wiegert EJ, Billing LM, DiOrio M. Algal bloom-associated disease outbreaks among users of Freshwater Lakes - United States, 2009-2010. MMWR. 2014;63(1):11-5.

31. Hoagland P, Jin D, Polansky LY, Kirkpatrick B, Kirkpatrick G, Fleming LE, Reich A, Watkins SM, Ullmann SG, Backer LC. The costs of respiratory illnesses arising from Florida Gulf Coast Karenia brevis blooms. Environ Health Perspect. 2009:117(8):1239-43.

32. DeFlorio-Barker S, Arnold BF, Sams EA, Dufour AP, Colford JM Jr, Weisberg SB, Schiff KC, Wade TJ. Child environmental exposures to water and sand at the beach: findings from studies of over 68,000 subjects at 12 beaches. J Exp Sci Environ Epidemiol. 2017:jes201723.

33. Arnold BF, Wade TJ, Benjamin-Chung J, Schiff KC, Griffith JF, Dufour AP, Weisberg SB, Colford JM Jr. Acute gastroenteritis and recreational water: highest burden among young US children. Am J Public Health. 2016;106(9):1690-7. 
34. Dorevitch S, Deflorio-Barker S, Jones R, Liu L. Water quality as a predictor of gastrointestinal illness following incidental contact water recreation. Water Res. 2015;83:94-103.

35. Wade TJ, Sams E, Haugland R, Brenner KP, Li Q, Wymer L, Molina M, Oshima K, Dufour A. Report on 2009 National Epidemiologic and environmental assessment of recreational water epidemiology studies: Office of Research and Development. Washington: Edited by Agency USEP; 2010b.

36. Collier SA, Wade TJ, Sams EA, Hlavsa M, Dufour AP, Beach MJ. Swimming in the USA: beachgoer characteristics and health outcomes at US marine and freshwater beaches. J Water Health. 2015;13(2):531-43.

37. Lin CJ, Wade TJ, Sams EA, Dufour AP, Chapman AD, Hilborn ED. A prospective study of marine phytoplankton and reported illness among recreational beachgoers in Puerto Rico, 2009. Environ Health Perspect. 2016; 124(4):477.

38. Council NRD: Testing the waters 2014: a guide to water quality at vacation beaches [https://www.nrdc.org/resources/testing-waters-2014-guide-waterquality-vacation-beaches]. Accessed 21 Apr 2017.

39. Fleisher JM, Kay D. Risk perception bias, self-reporting of illness, and the validity of reported results in an epidemiologic study of recreational water associated illnesses. Mar Pollut Bull. 2006;52(3):264-8.

40. US EPA (U.S. Environmental Protection Agency): Beach Grants [http://www2. epa.gov/beach-tech/beach-grants]. Accessed 15 Dec 2015.

\section{Submit your next manuscript to BioMed Central} and we will help you at every step:

- We accept pre-submission inquiries

- Our selector tool helps you to find the most relevant journal

- We provide round the clock customer support

- Convenient online submission

- Thorough peer review

- Inclusion in PubMed and all major indexing services

- Maximum visibility for your research

Submit your manuscript at www.biomedcentral.com/submit 